\title{
Evaluation of Emission Factors for New Technology S. I. Euro 4 Cars
}

\author{
Giovanni Meccariello, Livia Della Ragione, \\ Maria Antonietta Costagliola and Maria Vittoria Prati \\ Istituto Motori CNR, Naples, Italy
}

\begin{abstract}
This research attempted to analyze the environmental impact of two available non-conventional vehicle technologies, highlighting the benefits in terms of emissions and fuel consumption reduction with respect to conventional vehicles. Moreover, tests were compared with predicted emissions of the conventional gasoline technology provided by the kinematic model developed. Results show that cold start strongly affects the emissions of $\mathrm{CO}$, THC and $\mathrm{NO}_{X}$, which become very low during hot driving cycle. The existing emission model cannot be used to obtain a satisfactory prediction for hybrid car. But it could be proved that KEM emission model allows us to predict emission factor for conventional car and compressed natural gas. However, it is concluded that new experimental campaign with new technological cars might be interesting for future model developments.
\end{abstract}

Keywords: hybrid car, CNG car, exhaust emission factors, emission model

\section{Introduction}

Although more stringent emission standards and technological improvements have led to a remarkable reduction in emission levels for new cars, exhausts of vehicles still influence the urban air quality [1]. Moreover, the EU Commission wants to ensure that Europe meets its greenhouse gas (GHGs) emission targets under the Kyoto Protocol and beyond, promoting the purchase of fuel-efficient vehicles. In fact, in the EU member countries, transport has contributed to $21 \%$ of the total GHGs in 2007. Carbon dioxide is the main contributor to road transport GHG emissions (93\% in 2007) [2].

As a result, several non-conventional motorisations are becoming more popular than in the past $[3,4,5]$. Among these, hybrid technology has been proven effective in view of improving the fuel efficiency and reducing air pollution due to its assisted propulsion of an electric engine [6]. The alternative fuels characterised by a lower carbon to hydrogen ratio, like compressed natural gas $(\mathrm{CNG})$, constitute a potential manner for $\mathrm{CO}_{2}$ emission abatement $[7,8]$. The aim of this paper is to characterise emissive behaviour of two available non-conventional vehicle technologies, highlighting the benefits in terms of emission and fuel consumption reduction with respect to conventional spark-ignition (S.I.) cars. For this purpose, several experimental tests were performed on two gasolineelectric hybrid cars and a bi-fuel vehicle fuelled with compressed natural gas (CNG). The three non-conventional vehicles, approved according to Euro 4 standards, were tested on a chassisdynamometer bench during type-approval and real driving cycles for computing emission factors of carbon monoxide, hydrocarbons, nitrogen oxides and carbon dioxide. Although laboratory tests are essential to building emission models, especially for new technology cars, the models allow us to do an evaluation of emission factors in different kinematic conditions of different driving cycle which avoids full laboratory tests. Experimental hot emission factors were compared with those estimated for conventional Euro 4 passenger cars by KEM (Kinematic Emission Model), an emission model developed in Istituto Motori - CNR in the framework of EU FP5 Artemis project [9] and by the COPERT 4 model [10]. KEM allows us to predict emission factor at different kinematic conditions represented by driving cycles (DCs) [11], with respect to the COPERT 4 which only uses the mean speed as model input parameter. 


\section{Methodology}

Tested vehicle characteristics, driving cycles, measurement set-up and the modelling approach of KEM emission model will be detailed in the next section. The skills of COPERT 4 emission model are detailed in COPERT 4.

\subsection{Experimental Approach}

Three non-conventional Euro 4 passenger cars were tested on a chassis-dynamometer bench for characterizing regulated emissions and fuel consumption. The fleet was composed of two samples of gasoline-electric hybrid (Honda Civic hybrid) and a bi-fuel gasoline/natural gas (CNG) (Fiat Punto). Their main characteristics are described in Table 1. The Honda Civic is equipped with a parallel hybrid configuration, with the electric motor that assists the gasoline engine during take-off whilst the acceleration and energy are also recaptured by the same motor serving as a generator during slowing down or braking. This system incorporates an idlestop feature that shuts off the engine at traffic lights [12]. The two samples of hybrid technology will be considered separately because they belong to different series of production (Series 2007 and Series 2009). This aspect will explain some differences between emissive behaviour which will be highlighted in the experimental section.

The Fiat Punto is equipped with a three-way catalyst for pollutants abatement during both fuelling modes (gasoline and compressed natural gas). In this paper, only data related to $\mathrm{CNG}$ configuration are discussed.
Tests were performed on a Schenck chassis dynamometer to simulate the vehicle road load power demand as a function of speed and the inertia of vehicle. During execution of the driving cycle, the total exhaust stream was collected and diluted using a positive displacement pumpconstant volume sampler (PDP-CVS) dilution system. A Horiba Mexa $7200 \mathrm{H}$ gas analyzer was utilized to measure diluted exhaust concentrations of carbon monoxide (CO), total unburnt hydrocarbons (THC), nitrogen oxides $\left(\mathrm{NO}_{\mathrm{X}}\right)$ and carbon dioxide $\left(\mathrm{CO}_{2}\right)$. The modal analysis of gases concentrations at the raw exhaust was performed by using the Portable Emission Measurement System SEMTECH analyzer equipped with an exhaust flow meter (EFM).

Emissions were tested over the New European Driving Cycle (NEDC), performed in cold start conditions, as prescribed by European legislation, and during a real world driving cycle, called Common Artemis Driving Cycle-CADC $[13,14]$, driven in hot start conditions. Their speed profiles, with mean speed of DCs, are displayed in Figures 1-4. NEDC is composed of four urban modes (UDC), with a maximum speed of $50 \mathrm{~km} / \mathrm{h}$, and an extra-urban one (EUDC) reaching $120 \mathrm{~km} / \mathrm{h}$. CADC is composed of three different DCs (Artemis Urban, Artemis Road and Artemis Motorway) each representative of a specific traffic situation from congested to fluent. After the engine has started, all the Artemis DCs include a pre-conditioning phase not belonging to the sampling phase.

All the vehicles were tested during NEDC and Artemis Urban, whereas Artemis Road and Motorway were executed with Honda Civic hybrid Series 2007.

\begin{tabular}{|c||c|c|c|c|c|c|}
\hline Q.ty & Vehicle & Engine type & $\begin{array}{c}\text { Engine } \\
\text { displacement, } \\
\mathrm{cm}^{3}\end{array}$ & $\begin{array}{c}\text { Power, } \\
\mathrm{kW}\end{array}$ & $\begin{array}{c}\text { After treatment } \\
\text { devices }\end{array}$ & Transmission \\
\hline \hline $\mathbf{2}$ & $\begin{array}{c}\text { Honda Civic Hybrid } \\
\text { Series 2007 and } \\
\text { Series 2009) }\end{array}$ & $\begin{array}{c}\text { Gasoline engine, } \\
\text { multiport sequential } \\
\text { fuel injection } \\
\text { i-VTEC with } \\
\text { Electric Hybrid }\end{array}$ & 1339 & $\begin{array}{c}85 \\
(70+15)\end{array}$ & $\begin{array}{c}\text { Exhaust Gas } \\
\text { Recirculation } \\
\text { (EGR) plus } \\
\text { TWC }\end{array}$ & automatic \\
\hline $\mathbf{1}$ & $\begin{array}{c}\text { Fiat Punto 60 } \\
\text { Natural Power }\end{array}$ & $\begin{array}{c}\text { Gasoline engine, } \\
\text { electronic and } \\
\text { sequential MPI }\end{array}$ & 1242 & 38 & $\begin{array}{c}\text { Three Way } \\
\text { Catalyst } \\
\text { (TWC) }\end{array}$ & 5-speed manual \\
\hline
\end{tabular}

Table 1. Characteristics of vehicles. 


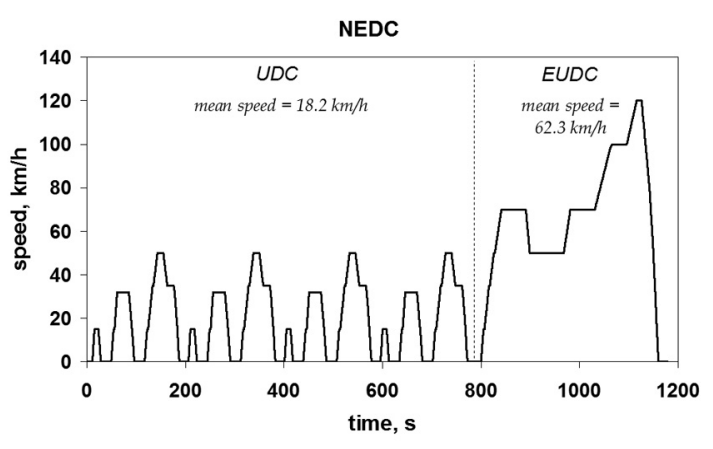

Figure 1. Speed profile of NEDC DC.

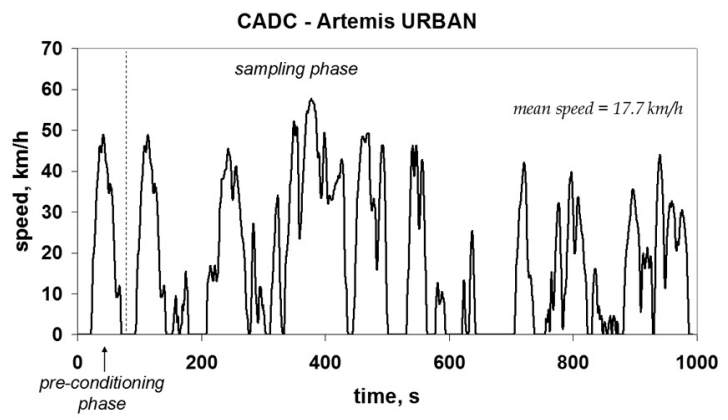

Figure 2. Speed profile of CADC Urban DC.

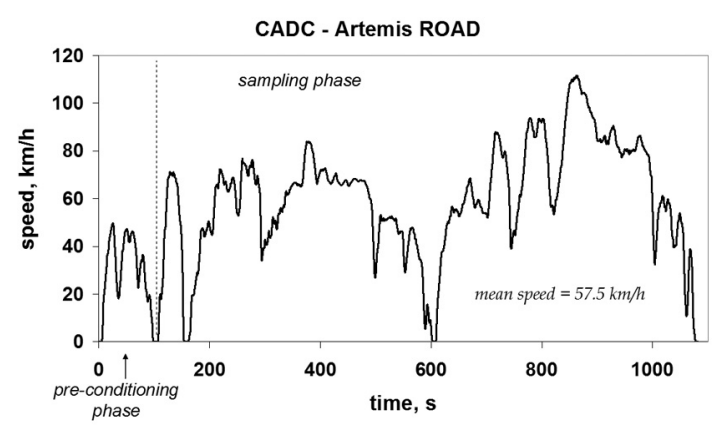

Figure 3. Speed profile of CADC Road DC.

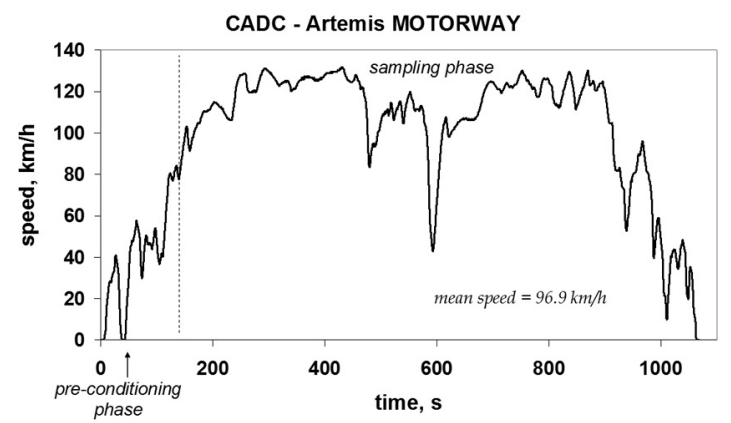

Figure 4. Speed profile of CADC Motorway DC.

\subsection{Modelling Approach}

The Kinematic Emission Model was developed by Istituto Motori-CNR in the framework of the FP5 European ARTEMIS Project [9] where some studies were carried out to take into account driving behavior and to relate emissions with kinematic characteristics. The model is able to calculate emission factor [15] taking into account a large number of parameters to characterize the kinematics of DCs. In the emission modelling context the dimensionality consideration could be probed by PLS (Partial Least Squares) multivariate regression method. It leads to a very powerful and flexible emission model, although rather complex in statistical and mathematical terms.

PLS regression method is able to consider the relation within $\mathrm{Y}$ variables (i.e. emission data), within $\mathrm{X}$ variables (i.e. kinematic driving cycle parameters), and last among Y's and X's [16].

Input kinematic parameters, are able to characterize standstill, acceleration and deceleration, as well as constant speed cruise phases of vehicle motion [17].

Following previous studies $[15,16]$ two blocks of $\mathrm{X}$ variables were identified considering two potential causes of variability in emissions for a driving cycle: energy expenditure from the vehicle in the cycle and the acceleration events at different speeds.

The regression equation presented in this application refers to the first block of variables. Its expression is:

$$
\begin{aligned}
\ln \mathrm{Y}_{i j} & =\mathrm{a}_{0}+\mathrm{a}_{1} \mathrm{MV}+\mathrm{a}_{2} \mathrm{MV}^{2}+\mathrm{a}_{3} \mathrm{MV}^{3} \\
& +\mathrm{a}_{4} \mathrm{MVA} \text { _POS }+\mathrm{a}_{5} \text { Trunning } \\
& +\mathrm{a}_{6} \text { Tidle }+\mathrm{a}_{7} \text { Invdist }+\varepsilon_{\mathrm{ij}}
\end{aligned}
$$

where $M V$ is mean speed, $M V^{2}$ is mean square speed and $M V^{3}$ is mean cubic speed; $M V A \_P O S$ is the mean product of instantaneous speed $(v)$ and acceleration $(a)$, calculated for positive values of a and v; Trunning is the running time and Tidle is the idle time of the driving cycle; Invdist is the reciprocal of the trip length, $\mathrm{a}_{0}$ is a constant and $\mathrm{a}_{1}-\mathrm{a}_{7}$ are the regression coefficients. 


\section{Results}

This section presents the experimental results of emission factors measured at the exhaust of the Euro 4 non-conventional passenger cars. These results are compared with emissions predicted by KEM and COPERT 4 models used to estimate emissions of conventional Euro 4 S.I. passenger cars.

\subsection{Experimental Emission Factors}

$\mathrm{CO}, \mathrm{THC}, \mathrm{NO}_{\mathrm{X}}$ and $\mathrm{CO}_{2}$ experimental values (expressed in $\mathrm{g} / \mathrm{km}$ ), measured at the exhaust of the three cars during different DCs, are reported in Figures 5-8. Data are the mean values of three repetitions; the repeatability of tests is explained by the error bars. Urban (UDC) and extra-urban (EUDC) phases of the European type approval driving cycle are separately considered; moreover, in order to underline the cold start contribution, UDC is further divided in two parts: "UDC cold" refers to the first two modules of UDC phase, and "UDC hot" to the last two ones. It is evident that cold start gives the major contribution to total $\mathrm{CO}$ and THC emissions. The increase due to the cold start (UDC cold versus UDC hot) ranges between $93-98 \%$ for CO and $66-99 \%$ for THC. The emission behavior of these new vehicle technologies suggests that the strong contribution to the emissions of incomplete combustion products comes from the fuel enrichment and from the catalyst light-off time, occurring during cold start phase. NOX cold start extra-emissions, instead, are visible only for the hybrid cars; the CNG vehicle produces comparable $\mathrm{NO}_{\mathrm{X}}$ emissions during both UDC phases. The reason probably lies in the tuning of the engine spark advance of hybrid engine, higher than CNG one. The higher spark advance causes higher level of $\mathrm{NO}_{\mathrm{X}}$ engine production also at the low temperature, typical of the cold start. The emission reduction measured in UDC hot is due to the activation of the catalyst towards $\mathrm{NO}_{\mathrm{X}}$ emissions. For $\mathrm{CNG}$ vehicle, instead, $\mathrm{NO}_{\mathrm{X}}$ production in the engine is mostly influenced by the combustion temperature; the low temperature occurring during the cold start explains the low $\mathrm{NO}_{\mathrm{X}}$ emissions, even though the catalyst is not yet working.

Cold start influences also $\mathrm{CO}_{2}$ emissions, especially for hybrid vehicles; in fact the "idle-stop" does not operate if the internal combustion engine has not yet warmed up [18]. In other words, for hybrid technology the higher $\mathrm{CO}_{2}$ emissions during UDC cold are justified not only by the presence of the cold start enrichment, but also by a lower time in engine-off condition respect on UDC hot.

Looking at hot start DCs, CO emissions of $\mathrm{CNG}$ vehicle reach the maximum value during EUDC and are comparable during both urban patterns (UDC and Artemis Urban); the hybrid vehicles show very low $\mathrm{CO}$ emissions during UDC and EUDC and an increasing trend during real world DCs (Artemis Road and Motorway). THC emissions are, generally, very low. In some cases, it was not possible to measure the emission factor because concentrations were comparable with background levels (i.e. THC during EUDC for hybrid vehicle). NOX emissions for hybrid vehicles become very low during CADC. Concerning $\mathrm{CO}_{2}$ emissions and the estimated fuel consumption, high speed driving cycles (i.e. EUDC and Artemis Motorway) represent the most fuel saving pattern whereas low speed real driving cycle (Artemis Urban) the most fuel demanding. Rapid accelerations and low cruising time make CADC the most critical driving cycle for pollutant emissions and fuel consumption. It has to be pointed out that the two series of hybrid vehicles present different $\mathrm{CO}_{2}$ emissions and fuel consumption during hot driving cycles. Series 2007 produces, in fact, higher emissions than series 2009. This is explained by a lower time driven with internal combustion engine in off condition.

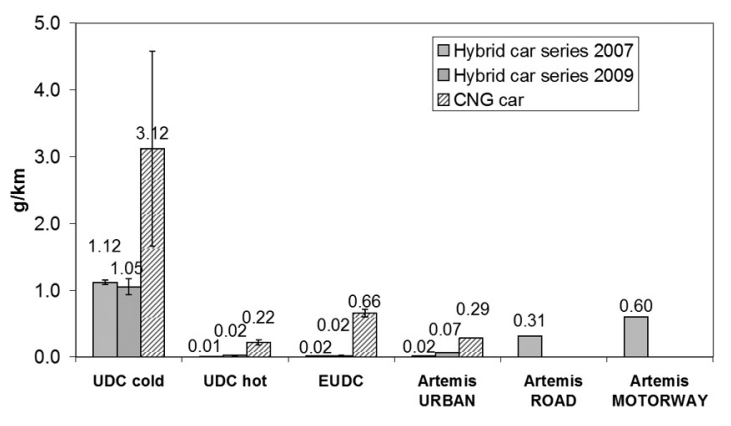

Figure 5. CO emissions during DC. 


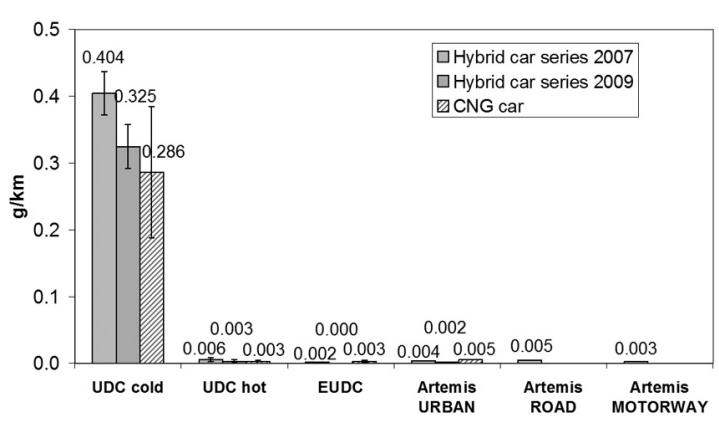

Figure 6. THC emissions during DC.

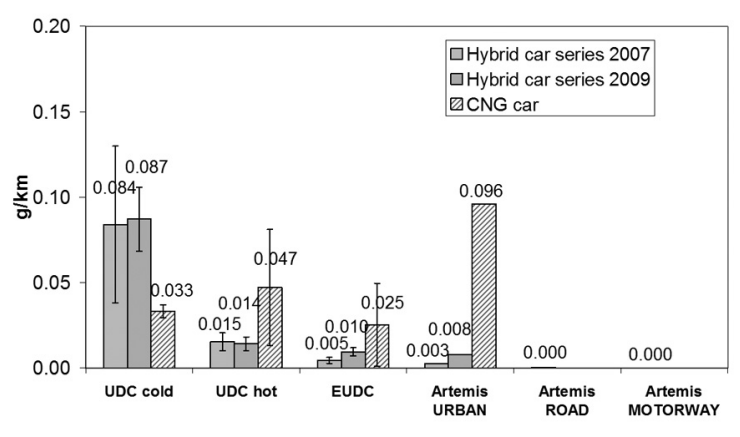

Figure 7. $\mathrm{NO}_{\mathrm{X}}$ emissions during $\mathrm{DC}$.

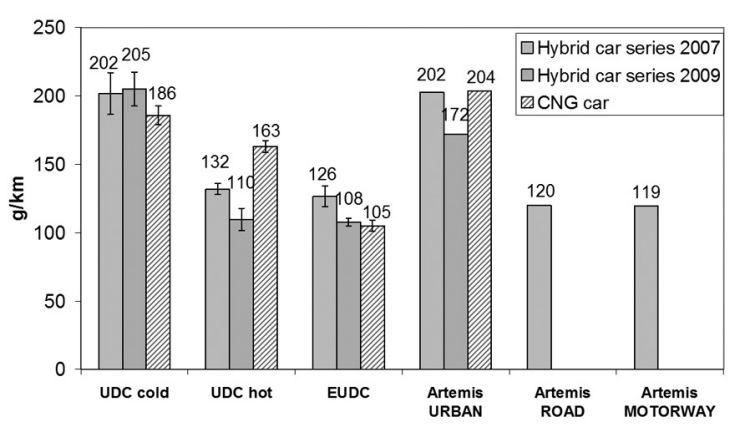

Figure 8. $\mathrm{CO}_{2}$ emissions during DC.

\subsection{Comparison with Emission Factors by KEM and COPERT 4 Models}

Experimental results of hot emission factors relative to the three Euro 4 non-conventional passenger cars are compared with emission factors obtained by KEM and COPERT 4 models. Both models were used to calculate emissions for conventional Euro 4 S.I. passenger cars. Moreover, COPERT 4 also provided emissions for Euro 4 hybrid vehicles.
The case study considered by KEM consists of the following 10 conventional car models in the range of engine capacity up to $2000 \mathrm{~cm}^{3}$ : Mazda 6 1.8, Audi A2 1.6 FSI, Toyota Corolla Saloon 1.4, Skoda Fabia, Volkswagen Golf, Volkswagen Golf 2.0, Skoda Octavia 2.0, Volkswagen Touran 1.6 FSI, Toyota Toyota Yaris 5-Türig 1.0 Vti, Opel Vectra.

COPERT 4 provides emission factors as a function of the driving cycles mean speed for each vehicle category, fuel type, emission standard and engine capacity. For our purposes, Euro 4 S.I. conventional and hybrid passenger cars were taken into account. $\mathrm{CO}, \mathrm{THC}$ and $\mathrm{NO}_{\mathrm{X}}$ emissions for conventional cars are not grouped according to the engine capacity, whereas fuel consumption and consequently $\mathrm{CO}_{2}$ refer to an engine capacity lower than $1400 \mathrm{~cm}^{3}$ and between $1400-2000 \mathrm{~cm}^{3}$. The few available data for hybrid cars in COPERT 4 methodology refer to vehicles with engine capacity lower than $1600 \mathrm{~cm}^{3}$.

In order to compare the two different methodologies with experimental results, data were analyzed according to the mean speed of driving cycles.

Figures 9-12 resume respectively CO, THC, $\mathrm{NO}_{\mathrm{X}}, \mathrm{CO}_{2}$, emission factors derived by models and experimental measurements. Each figure displays the experimental Artemis database (DB) observation (star symbol in green *) used to fit the KEM regression model, the experimental data of two hybrid cars (square symbol in light blue $\mathbf{\square})$, the experimental data of Fiat Punto (dot symbol in orange $\bullet$ ), the trend supplied by the COPERT 4 model for the specific car technology (respectively conventional gasoline in blue dashed curve - - and hybrid in red curve -), the predicted values obtained by the KEM model (triangle symbol in red $\boldsymbol{\Delta}$ ) for all DC analyzed.

We can observe that KEM shows a good fitness of the model for these pollutants and also the prediction trends respect to COPERT 4 curves. The KEM model synthesizes the effect of all input variables used. COPERT 4 curves show a clear difference from the two analyzed technology (conventional and hybrid) and the KEM model, not developed on hybrid technology, is not able to produce a significant prediction.

Looking at $\mathrm{CO}$ emissions (Figure 9), it was observed that emissions relative to the hybrid cars 
are included in the variability of conventional Euro 4 S.I. data. Experimental data relative to Honda Civic hybrid are, in fact, in some cases close to the lowest emissions provided by COPERT 4 curve for hybrid vehicles, but in other cases they become more similar to the emissions of conventional S.I. cars. CNG vehicle, instead, produces $\mathrm{CO}$ emissions generally higher than those of conventional cars at the same speeds, with an increasing difference when increasing the mean speed.

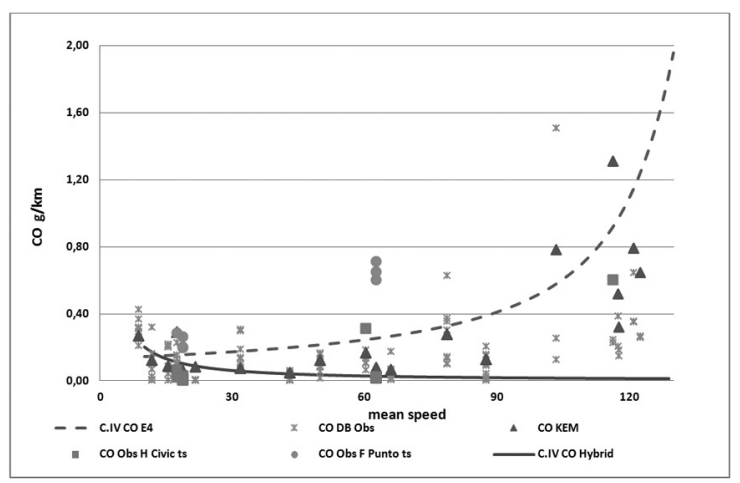

Figure 9. Estimated and measured $\mathrm{CO}$ emissions for Euro 4 S.I. cars.

The same behavior is not visible for THC emissions (Figure 10). As already highlighted in the section of experimental results, hot THC emissions of both tested technologies are very low. The comparison with conventional vehicles states, in fact, that the hybrid and CNG cars produce THC emissions close to the minimum predicted values relative to the COPERT 4 curve for hybrid vehicles.

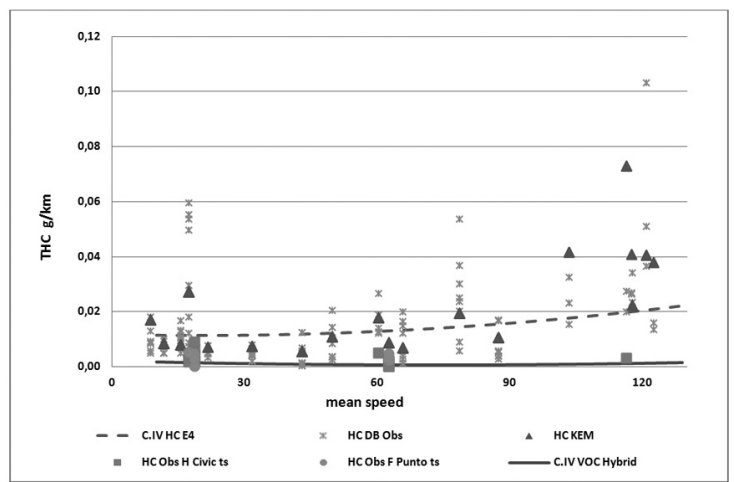

Figure 10. Estimated and measured THC emissions for Euro 4 S.I. cars.

A high variability of data marks $\mathrm{NO}_{\mathrm{X}}$ emissions of CNG cars (Figure 11). In this case, experimental data are shared out between predicted values by the several models. The KEM model better fits this variability than COPERT $4 . \mathrm{NO}_{\mathrm{X}}$ emissions of hybrid cars are always lower than conventional ones.

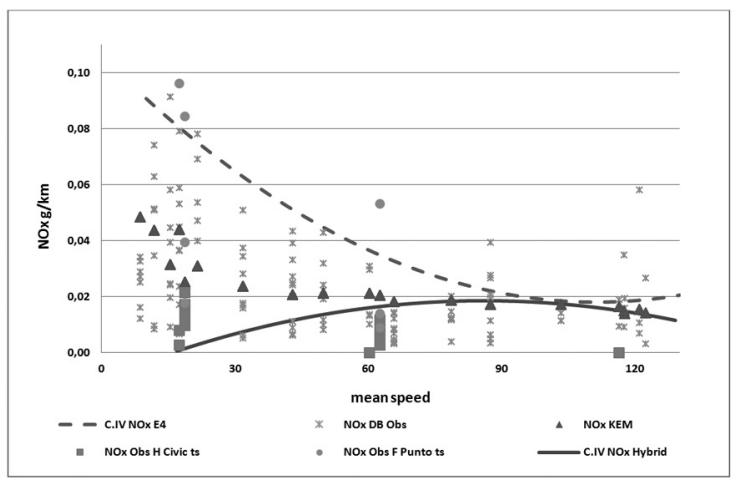

Figure 11. Estimated and measured NOx emissions for Euro 4 S.I. cars.

Regarding $\mathrm{CO}_{2}$ emissions (Figure 12), the experimental data confirm that the new technologies present lower emissions than those relative to the conventional ones. The difference is more evident at low speed. The lowest emissions values are relative to the tested Honda Civic and are well explained by COPERT 4 curve provided for Euro 4 gasoline hybrid passenger cars. In the figure we also illustrate the two trends supplied from the $\mathrm{CO}_{2}$ COPERT 4 model to differentiate the 1.4-2.0 displacement (orange curve - ) from the car with displacement less than 1.4. (blue dashed curve - -). $\mathrm{CO}_{2}$ emission reduction for hybrid vehicles respect on conventional ones is maximum at low speed (up to 50\%) and becomes almost $10 \%$ in correspondence of high speeds. CNG car results in $20 \%$ reduction in $\mathrm{CO}_{2}$ relative to conventional S.I. cars.

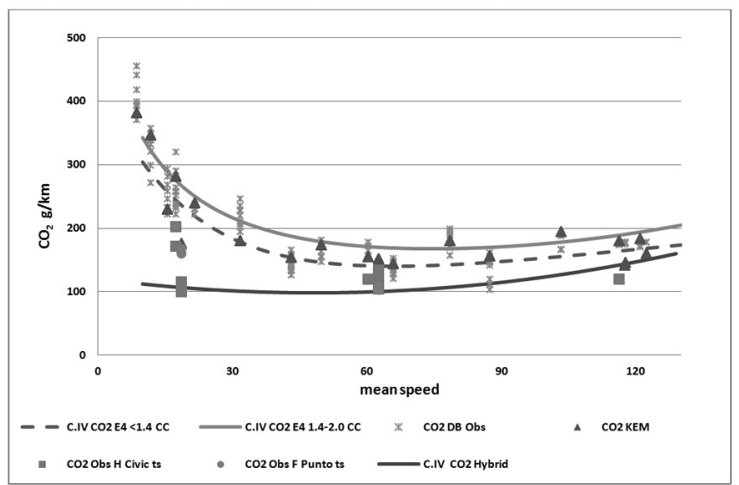

Figure 12. Estimated and measured $\mathrm{CO}_{2}$ emissions for Euro 4 S.I. cars. 


\section{Conclusions}

Several dynamometer tests were carried out to measure emissions at the exhaust of three Euro 4 non-conventional passenger cars (two gasolineelectric hybrid and a CNG fuelled vehicles). Cold start represents a significant contribution to total $\mathrm{CO}$ and THC emissions for both tested technologies. $\mathrm{NO}_{\mathrm{X}}$ emissions are influenced by cold start only for hybrid cars, whereas hot and cold emissions of CNG vehicles are quite comparable. $\mathrm{CO}$ shows an increasing trend when mean speed increases whereas $\mathrm{NO}_{\mathbf{X}}$ have a decreasing trend when moving from UDC to Artemis Motorway driving cycle. $\mathrm{CO}$ and $\mathrm{NO}_{\mathrm{X}}$ emissions of $\mathrm{CNG}$ vehicles are higher than those of hybrid ones; THC, instead, are very similar. Regarding $\mathrm{CO}_{2}$ and consequently the fuel consumption, the three tested cars have the same behaviour; they decrease when the mean speed of driving cycles increases. Experimental data obtained with new technology Euro 4 cars were also compared with the predicted value of a meso-scale emission model developed by Istituto Motori for conventional S.I. cars and COPERT 4. The hybrid cars, in hot driving conditions, are very low emitters if compared to conventional cars. The results obtained can be used as a first estimation toward emission inventories for the vehicles considered in this investigation, in fact for hybrid and CNG fuelled cars very few data are available in literature. The conventional emission model cannot be usefully used to obtain a good emission prediction for hybrid technology car. The modeling analysis highlighted the need of KEM for a specific data set with hybrid cars to build a specific model for this category.

Instead, for CNG fuelled cars the emission behaviour is quite similar to the conventional cars. Generally, for the CNG car, the predicted KEM values are more accurate than COPERT 4 model, except for $\mathrm{CO}_{2}$ emission where the observed values are lower with respect to the conventional cars. This, also, because the CNG has lower carbon content and a net reduction in carbon can be achieved compared with petrol or diesel fuel; hence, also for $\mathrm{CNG}$, a specific model improvement for $\mathrm{CO}_{2}$ emission, both for KEM and COPERT 4, is required.

Although these conclusions are based on measurement results from only few vehicles, thanks to the flexibility of the KEM model, an excellent hybrid and CNG prediction model is expected after suitable experimental campaign on this class of new technology vehicles.

\section{References}

[1] A. AlKadRY, A. M. KHAN, Greenhouse Gas Reduction Potential of Advanced Traffic Control. Journal of Advanced Transportation, 34(3) (2002), pp. 347-368, ISSN 0197-6729.

[2] European Environmental AgEnCy, Annual European Community greenhouse gas inventory 1990 2007 and inventory report 2009. EEA technical report, no. 04/2009.

[3] C. SILVA, M. Ross, T. FARIAS, Evaluation of energy consumption, emissions and cost of plug-in hybrid vehicles. Energy Conversion and Management, 50(7) (2009), 1635-1643.

[4] T. KATRAŠNIK, Hybridization of powertrain and downsizing of IC engine - A way to reduce fuel consumption and pollutant emissions - Part 1. Energy Conversion and Management, 48(5) (2007), 1411-1423.

[5] T. KATRAŠNIK, Hybridization of powertrain and downsizing of IC engine - analysis and parametric study - Part 2. Energy Conversion and Management, 48(5) (2007), 1424-1434.

[6] M. Wise, G. P. KYle, J. DoOleA, S. H. KIM, (2009). The impact of electric passenger transport technology on the demand for coal-fired power with CCS under a climate policy. Energy Procedia 1(1), pp. 4355-4362.

[7] J. M. LÓPEZ, Á. GóMEZ, F. APARICIO, F. J. SÁNCHEZ, Comparison of GHG emissions from diesel, biodiesel and natural gas refuse trucks of the City of Madrid. Applied Energy, 86(5) (2009), pp. 610615.

[8] O. Xunmin, Z. Xiliang, C. ShiYan, Scenario analysis on alternative fuel/vehicle for China's future road transport: Life-cycle energy demand and GHG emissions Energy Policy, 38(8) (2010).

[9] R. Joumard, J. M. André, M. RAPOne, M. ZALlinger, N. KlJun, M. ANDrÉ, S. SAMARAS, S. Roujol, J. LaurikKo, M. WeilenManN, K. MARKEWITZ, S. GEIVANIDIS, D. AJTAY, L. PATUREL, Emission factor modelling and database for light vehicle. Artemis deliverable 3. (2007), Inrets report, Bron, France, no. LTE 0523, p. 237.

[10] COPERT 4, Software Program for Calculation of Air Pollutant Emissions from Road Transport, Thessaloniki (Greece): Aristotle University of Thessaloniki, version 6.1, 2009. 
[11] M. Rapone, M. V. Prati, G. Meccariello, L. Della Ragione, M. A. Costagliola, A Novel Statistical Model for the Evaluation of Vehicle Emission Factors. Application to a Euro III Gasoline Car Fleet, Proceedings of the $7^{\text {th }}$ International Conference on Engines for Automobile. Ice2005. Capri, Naples. September 2005. Sae Paper 200524-024.

[12] F. Nemry, G. Leduc, I. Mongelli, A. Uihlein, JRC Scientific and Technical Report on Environmental Improvement of Passenger Cars (IMPROcar). EU Report 23038, (2008).

[13] M. Andrè, R. Joumard, R. Vidona, P. TASSEla, P. PERRET, Real-world European driving cycles, for measuring pollutant emissions from high- and lowpowered cars. Atmospheric Environment, 40 (31) (2006), pp. 5944-5953.

[14] G. Fontaras ET AL., Experimental evaluation of hybrid vehicle fuel economy and pollutant emissions over real-world simulation driving cycles. Atmospheric Environment, 42 (2008), pp. 40234035.

[15] M. Rapone, M. V. Prati, M. A. Costagliola, L. Della Ragione, G. MecCARIEllo, Emission Factors Determination of Euro III 1,200- to 1,400-cc Petrol Passenger Cars with a PLS Multivariate Regression Model. Journal Environmental Modelling and Assessment, Springer, Vol. 13 (2008), pp. 383-392.

[16] M. TENEnhaus, La regression PLS Theorie et Pratique. Editions Technip Paris, 1998.

[17] L. Della Ragione, G. Meccariello, Prediction of Pollutant Emission Using Partial Least Squares Method. Proceedings of the ITI $201032^{\text {nd }}$ Int. Conf. on Information Technology Interfaces, (2010) Cavtat, Croatia, ISBN 978-953-7138-18-9, ISSN 1330-1012, pp. 521-526.

[18] M. Thornton, S. Jorgensen, B. Evans, K. Wright, Cold-Start and Warm-Up Driveability Performance of Hybrid Electric Vehicles Using Oxygenated Fuels. Proceedings of the SAE Powertrain \& Fluid Systems Conference \& Exhibition, (2003) Pittsburgh, SAE Paper 2003-01-3196.

Received: June, 2012 Accepted: August, 2012

Contact addresses:

Giovanni Meccariello Istituto Motori CNR via Marconi 8 80125 Naples Italy

e-mail: g.meccariello@im.cnr.it

Livia Della Ragione Istituto Motori CNR via Marconi 8 80125 Naples Italy

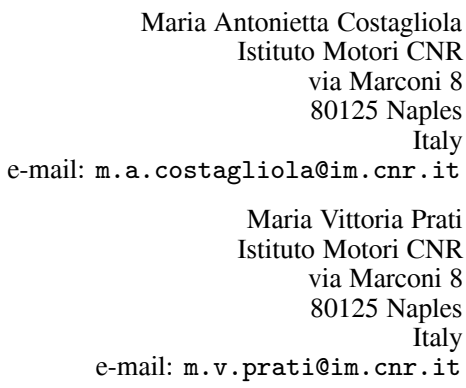

GIOVANNI MECCARIELLO graduated in 1999 in economics from the University of Naples "Federico II" (Italy). He received his PhD in 2005 from the Department of Transportation Engineering "Luigi Tocchetti" of the University of Naples "Federico II" (Italy). He is a researcher of vehicle performance and emissions for sustainable transportation at Istituto Motori of National Research Council of Italy. His research field of interest includes statistical and soft computing methods for modeling driving cycles and emissions of vehicles in real-use, with special concern for vehicle mission profile in urban areas and exhaust emissions evaluation. He is working with SAS System, particularly in the field of multivariate statistical analysis with SAS/STAT ${ }^{\circledR}$ and SAS/GRAPH®.

LIVIA DELLA RAGIONE graduated in 1988 in mathematics from the University of Naples "Federico II" (Italy). Presently, she is a researcher of CNR-IM Her main research activities concern the environmental impact of vehicles. Her principal areas of interest include multivariate statistical analysis and time series analysis. The main research subjects are vehicle mission profile in urban areas and the development of methods for the evaluation of exhaust emissions as a function of vehicle operating conditions in the traffic. In this context she has developed some statistical codes applied to determine driving cycles by vehicle speed records in the traffic obtained by instrumented cars performing planned. Also she is involved in the development of models for vehicular emission factors determination based on measurements of pollutant emissions. Dr. Della Ragione is responsible for research group working on "Statistical methods for driving cycle modelling and emission factors development".

MARIA ANTONIETtA COSTAGLIOLA graduated in 2001 in chemical engineering from the University of Naples Federico II. Actually she is a researcher in the National Council of Research. Her research activity is focused on the emission behaviour of two and four wheeler vehicles. In particular, she carried out vehicle chassis dynamometer and on-road tests in order to assess the influence of several parameters (such as kinematics, driving style, fuel type, car technology, after-treatment devices) on regulated and unregulated exhaust emissions and fuel consumption. Among unregulated pollutants, a great concern is given to particulate, characterised as mass, size distribution and chemical composition.

MARIA VITTORIA PRATI graduated in 1987 in chemical engineering from the University of Naples "Federico II" (Italy). Presently, she is a researcher of CNR-IM. Her main research activities concern the environmental impact for vehicles. She is responsible for emission laboratories for 2 and 4 wheeler vehicles where tests with vehicles on chassis dynamometer benches are performed under controlled conditions. She has experience in the characterization of gaseous, liquid and solid species emitted at the exhaust of engines/vehicles and in the particulate characterization (in terms of mass, dimension, number, size distribution, soot and organic fraction contribute). She is involved in experimental activities concerning on-board measurements of pollutant emissions and in the development of models for vehicular emission factors determination. 